\title{
Osteoporosis and Fragility in Elderly Patients
}

\author{
Paolo Falaschi, Andrea Marques, and Stefania Giordano
}

\subsection{Definition}

Osteoporosis is a systemic bone disease characterised by a reduction and qualitative alterations of the bone mass leading to increased risk of fractures. There are two primary forms of osteoporosis (types I and II): postmenopausal osteoporosis and senile osteoporosis, which appears with advancing age. Secondary forms of osteoporosis are associated with a vast range of diseases and drugs [1].

According to the World Health Organisation, the diagnosis of osteoporosis rests on densitometry, as described below in Sect. 3.7.1, with a T-score diagnostic threshold of $<-2.5[1,2]$.

This disease is progressive and if not diagnosed and treated (primary prevention) causes progressive fragility of the bones through a complex pathogenetic mechanism described in detail in Sect. 3.5. This acquired fragility of the skeleton increases the risk of fracture with low energy trauma or even spontaneously in the most severe

This chapter is a component of Part 1: Background.

For an explanation of the grouping of chapters in this book, please see Chapter 1: 'The Multidisciplinary Approach to Fragility Fractures Around the World-An Overview'.

\section{P. Falaschi $(\bowtie)$ \\ Fragility Fracture Network, Zurich, Switzerland \\ Sapienza University of Rome, Rome, Italy \\ e-mail: paolo.falaschi@fondazione.uniroma1.it}
A. Marques
RN at Rheumatology Department, Centro Hospitalar e Universitário de Coimbra,
Coimbra, Portugal
School of Nursing, Coimbra, Portugal
S. Giordano
RSA Salus, Rome, Italy 
cases. When a fragility fracture occurs a DEXA may not be necessary and the antiosteoporotic treatment can be started to reduce the risk of further fractures (secondary prevention).

\subsection{Epidemiology}

Osteoporosis is a disease that impacts significantly on society. Its incidence increases with age; in fact, it affects most of the population which has entered the eighth decade of life [1]. Common sites of osteoporotic fractures are the spine, hip, distal forearm and proximal humerus. All told, osteoporotic fractures occur in 2.7 million in men and women in Europe with high direct costs [3]. A recent estimate (for 2010) calculated the direct cost at 29 billion in the five largest EU countries (France, Germany, Italy, Spain and the UK) [4] and 38.7 billion in the 27 EU countries of the time [5]. Hip fractures cause acute pain and loss of function, and nearly always lead to hospitalisation. Recovery is slow, and rehabilitation is often incomplete, with many patients permanently institutionalised in nursing homes. Vertebral fractures may cause acute pain and loss of function but may also occur without serious symptoms. Distal radial fractures also lead to acute pain and loss of function, but functional recovery is usually good, at times excellent. It is widely recognised that osteoporosis and the fractures it causes are associated with increased mortality, with the exception of forearm fractures [6]. In the case of hip fractures, most deaths occur during the first 3-6 months following the event, of which $20-30 \%$ are causally related to the fracture itself [7]. For an extensive description of the epidemiological distribution of osteoporosis, fragility fractures and costs, see Chap. 2.

\subsection{The Anatomy of Bone}

Eighty percent of the adult human skeleton is composed of cortical bone, $20 \%$ of trabecular bone. Cortical bone is dense and solid and surrounds the space occupied by the marrow, whereas trabecular bone is composed of a honeycomb-like network of trabecular plates and rods interspersed throughout the bone-marrow compartment. Both cortical and trabecular bone are composed of osteons. Cortical osteons are called Haversian systems. Haversian systems are cylindrical in shape, approximately $400 \mathrm{~mm}$ in length and $200 \mathrm{~mm}$ in width at their base and form a branching network within the cortical bone [8].

Bone tissue is composed of cells (Osteoclast, osteoblast and osteocytes) and matrix [8].

Osteoclasts are the only cells known to be capable of resorbing bone. Activated multinucleated osteoclasts are derived from mononuclear precursor cells of the monocyte-macrophage lineage [9].

Osteoblasts: Osteoprogenitor cells give rise to and maintain the osteoblasts that synthesise new bone matrix on bone-forming surfaces, the osteocytes within the bone matrix supporting the bone structure, and the protective lining cells that 
cover the surface of the quiescent bone. Within the osteoblast lineage, subpopulations of cells respond differently to various hormonal, mechanical or cytokine signals [8].

Osteocytes: Osteocytes represent terminally differentiated osteoblasts and function within syncytial networks to support bone structure and metabolism. Osteocytes lie in lacunae within mineralised bone and create extensive filopodial processes within the canaliculi in mineralised bone. Osteocytes express several matrix proteins that support intercellular adhesion and regulate the exchange of mineral in the bone fluid within the lacunae and the canalicular network. Osteocytes are active during osteolysis and may function as phagocytic cells because they contain lysosomes [8].

The bone extracellular matrix is composed of between $85 \%$ and $90 \%$ of collagenous proteins. Bone matrix is mostly composed of type I collagen, with trace amounts of types III and V and FACIT collagens at certain stages of bone formation. FACIT collagens are members of the family of Fibril-Associated Collagens with Interrupted Triple Helices, a group of nonfibrillar collagens that serve as molecular bridges important for the organisation and stability of extracellular matrices [10].

Bone is composed of 50-70\% minerals, 20-40\% organic matrix, 5-10\% water, and $<3 \%$ lipids. The mineral content of bone is mostly hydroxyapatite $\left[\mathrm{Ca}_{10}\left(\mathrm{PO}_{4}\right)_{6}(\mathrm{OH})_{2}\right]$, with small amounts of carbonate, magnesium, and acid phosphate, with missing hydroxyl groups that are normally present. Matrix maturation is associated with the expression of alkaline phosphatase and several non-collagenous proteins, including osteocalcin, osteopontin, and bone sialoprotein. Bone mineral provides mechanical rigidity and load-bearing strength to bone, whereas the organic matrix provides elasticity and flexibility [8].

The term 'bone quality' is used in two senses in the literature: in one bone quality represents the sum of all the characteristics of bone that affect its ability to resist fracture (i.e. all aspects of bone size, shape and its material properties); in the other, bone quality refers to the influence of factors that affect fracture but are not accounted for by bone mass or quantity [11, 12]. Regardless of one's preference regarding a general definition of bone quality, bone quality remains a skeletal trait and since it is important in determining fracture risk it must play a role in determining the mechanical properties of bone, and therefore cannot account for any non-skeletal factors that may also contribute to fracture incidence such as the risk of falling or limitations of commonly used measurements of bone mass [13].

Following the hierarchic structure of the bone we can recognise the following determinants for bone quality: whole bone morphology (size and shape), spatial distribution of bone density, microarchitecture, porosity, cortical-shell thickness, lacunar number/morphology, number, size and distribution of the remodelling cavity, mineral and collagen distribution/alignment, type, amount and distribution of microdamage structure and cross-linking of collagen, mineral type and crystal alignment and collagen-mineral interfaces [14]. 


\subsection{The Physiology of Bone}

Modelling is the process by which bones change their overall shape in response to physiological influences or mechanical forces, leading to a gradual adjustment of the skeleton to the forces it encounters [15].

Bone remodelling is the process by which bone is renewed to maintain bone strength and mineral homeostasis. Remodelling involves continuous removal of discrete packets of old bone, replacement of these packets with newly synthesised matrix, and subsequent mineralisation of the matrix to form new bone. The main functions of bone remodelling are preservation of the mechanical strength of bone by replacing the older, micro-damaged bone with newer, healthier bone and calcium and phosphate homeostasis [8].

The remodelling cycle comprises four sequential phases: activation, resorption, reversal, formation [16, 17]. Activation involves recruitment and activation of mononuclear monocyte-macrophage osteoclast precursors from the circulation, lifting of the endosteum containing the lining cells off the bone surface, and fusion of multiple mononuclear cells to form multinucleated preosteoclasts. Preosteoclasts bind to the bone matrix via interactions between integrin receptors in their cell membranes and RGD (arginine, glycine, and asparagine)-containing peptides in matrix proteins, to form annular sealing zones around bone-resorbing compartments beneath multinucleated osteoclasts [8].

Osteoclast-mediated bone resorption takes only approximately 2-4 weeks during each remodelling cycle. Osteoclast formation, activation, and resorption are regulated by the ratio of receptor activator of NF- $\kappa \mathrm{B}$ ligand (RANKL) to osteoprotegerin (OPG) IL-1 and IL-6, colony-stimulating factor (CSF), parathyroid hormone, 1,25-dihydroxyvitamin D, and calcitonin [9, 18]. Resorbing osteoclasts secrete hydrogen ions via H+-ATPase proton pumps and chloride channels in their cell membranes into the resorbing compartment to lower the $\mathrm{pH}$ within the boneresorbing compartment to as low as 4.5, which helps mobilise bone mineral. Resorbing osteoclasts secrete tartrate-resistant acid phosphatase, cathepsin K, matrix metalloproteinase 9, and gelatinase from cytoplasmic lysosomes to digest the organic matrix, resulting in the formation of saucer-shaped Howship's lacunae on the surface of trabecular bone and Haversian canals in cortical bone. The resorption phase is completed by mononuclear cells after the multinucleated osteoclasts undergo apoptosis [19]. Upon completion of bone resorption, resorption cavities contain a variety of mononuclear cells, including monocytes, osteocytes released from bone matrix, and preosteoblasts recruited to begin the formation of new bone. The coupling signals linking the end of bone resorption to the beginning of bone formation are not totally clear [20]. It has also been proposed that the reversal phase may be mediated by the strain gradient in the lacunae. As osteoclasts resorb cortical bone in a cutting cone, the strain is reduced in front and increased behind, and in Howship's lacunae, the strain is highest at the base and less in surrounding bone at the edges of the lacunae. The strain gradient may lead to sequential activation of osteoclasts and osteoblasts, with osteoclasts activated by reduced strain and osteoblasts by increased strain. It has also been proposed that the osteoclast itself may play a role during reversal [21]. Bone formation takes approximately 
4-6 months to complete. Osteoblasts synthesise new collagenous organic matrix and regulate mineralisation of matrix by releasing small, membrane-bound matrix vesicles that concentrate calcium and phosphate and enzymatically destroy mineralisation inhibitors such as pyrophosphate or proteoglycans [22]. Osteoblasts surrounded by and buried within matrix become osteocytes with an extensive canalicular network connecting them to bone surface lining cells, osteoblasts, and other osteocytes, maintained by gap junctions between the cytoplasmic processes extending from the osteocytes [23]. At the completion of bone formation, approximately $50-70 \%$ of the osteoblasts undergo apoptosis, with the balance becoming osteocytes or bone-lining cells.

A critical advance in our understanding of skeletal biology of the last few years was the discovery of the role of $\mathrm{Wnt} / \beta$ catenin signalling in bone $[24,25]$. Wnt/ $\beta$ catenin signalling is activated by binding of Wnt proteins to receptor complexes composed of frizzled receptors and co-receptors of the low-density lipoprotein receptor-related protein (LRP) family, LRP5 and 6. This event stabilises $\beta$ catenin, induces its translocation to the nucleus, and activates gene transcription. This socalled canonical Wnt signalling pathway controls the differentiation of mesenchymal stem cells (MSC) restraining chondrogenic and adipogenic differentiation and favouring osteoblastic differentiation. Canonical Wnt signalling also promotes osteoblast maturation and survival of osteoblasts and osteocytes and inhibits osteoclast generation by increasing the expression in osteoblasts and osteocytes of osteoprotegerin (OPG), the decoy receptor of the receptor activator of Nfkb ligand (RANKL). Thus, activation of this pathway is critical for bone acquisition and maintenance through the increased bone formation and decreased resorption. Osteocytes are key players in the regulation of the canonical Wnt signalling pathway as producers and targets of Wnt ligands and as secretors of molecules that modulate Wnt actions $[25,26]$. A potent antagonist of Wnt signalling secreted by osteocytes is sclerostin, a protein encoded by the SOST gene, primarily expressed by mature osteocytes but not by early osteocytes or osteoblasts [27]. Sclerostin binds to the Wnt co-receptors LRP5/6 antagonising downstream signalling [28]. Sclerostin also interacts with LRP4, another member of the LRP family of proteins, which acts as a chaperone and is required for the inhibitory action of sclerostin on $W n t / \beta$ catenin signalling [29]. Absence of sclerostin expression or secretion in humans causes inherited high bone mass conditions characterised by exaggerated bone formation, including sclerosteosis, van Buchem disease and craniodiaphyseal dysplasia [25].

Osteoprotegerin (OPG), the decoy receptor for RANKL and therefore the inhibitor of bone resorption, is a Wnt/ $\beta$ catenin target gene [30]. Thus, genetic manipulation of $\mathrm{Wnt} / \beta$ catenin signalling leads to marked changes in OPG expression with consequent effects on resorption. Specifically, inactivation of $\mathrm{Wnt} / \beta$ catenin in mature osteoblasts/osteocytes decreases OPG and increases osteoclast differentiation and bone resorption [31-33]. Conversely, activation of Wnt/ $\beta$ catenin in osteoblasts increases OPG expression and reduces bone resorption $[31,32]$. Because sclerostin antagonises the $\mathrm{Wnt} / \beta$ catenin signalling pathway, it is not unexpected that changes in SOST/sclerostin expression might also modulate resorption by regulating OPG. In fact, neutralising anti-sclerostin antibodies increase bone formation 
and decrease bone resorption markers in experimental animals and humans, suggesting that the bone gain achieved results from the combination of enhanced bone formation and decreased bone resorption [34].

\subsection{Pathogenesis}

Peak bone mass is achieved between the ages of 16-25 in most people. After this age, bone mass decreases slowly but continuously [35].

There is epidemiologic evidence for substantial effects of nutrition and lifestyle on peak bone mass and fracture risk, not only during childhood and adolescence but even during gestation [36, 37].

Bone formation typically exceeds bone resorption on the periosteal surface, so bones normally increase in diameter with age. Bone resorption typically exceeds bone formation on the endosteal surface, so the marrow space normally expands as people age. Bone remodelling increases in perimenopausal and early postmenopausal women and then slows down with further ageing but continues at a faster rate than in premenopausal women. Bone remodelling is thought to increase mildly in ageing men [8].

Normal rates of bone loss are different in men and women. In men, bone mass is lost at a rate of $0.3 \%$ per annum, while in women this rate is $0.5 \%$. By way of contrast, bone loss after menopause, in particular during the first 5 years after its onset, can be as high as 5-6\% per annum [35].

Besides the difference in age at onset, types I and II osteoporosis have somewhat different effects on the kinds of bone lost. Type I appears to affect mostly trabecular bone, while type II affects both cortical and trabecular bone [35]. The cellular mechanism of type II osteoporosis is multifactorial. Factors involved are progressive dietary calcium deficiency, progressive inactivity $[35,38]$, and as in type I osteoporosis, decreases in oestrogen levels have been demonstrated in both elderly men and women to be an important cause of senile osteoporosis.

Normal cancellous bone is composed of both horizontal and vertical trabeculae. In the osteoporotic bone, there is a predisposition to loss of horizontal trabeculae. This leads to decreased interconnectivity of the internal scaffolding of the vertebral body. Without the support of crossing horizontal members, unsupported vertical beams of the bone easily succumb to minor loads [35].

\subsection{Risk Factors for Fragility Fractures}

Osteoporotic fractures are related to several risk factors (Table 3.1).

\subsubsection{BMD}

Several studies have demonstrated that the reduction of a single standard deviation in BMD corresponds to an increase in fracture risk of 1.5-3-fold [1]. However, fracture risk is not only related to BMD, consequently, T-score values alone are not 
Table 3.1 Summary of clinical risk factors $[1,2]$

\author{
Age \\ Female gender \\ Low body mass index \\ Previous fragility fracture, particularly of the hip, wrist and \\ spine \\ Parental history of hip fracture \\ Glucocorticoid treatment ( $\geq 5 \mathrm{mg}$ prednisolone daily or \\ equivalent for 3 months or more) \\ Current smoking \\ Alcohol intake of three or more units daily \\ Premature menopause \\ Vitamin D deficiency \\ Reduced calcium intake \\ Drugs \\ Osteoporosis-related pathologies (see Table 3.2) \\ Organ transplant
}

For an extensive description of risk factors see Chap. 14

sufficient to define the probability of fracture and determine when a patient needs to be treated [39]. Moreover, the majority of fractures occur in patients presenting with osteopenia (T-scores of -2.5 to -1.0 ) [40].

An interesting situation is the diabetic patient since type 2 diabetes is usually associated with a 5-10\% higher areal BMD than healthy subjects but despite that, they are at higher risk of fracture. It has been demonstrated that for a given T-score and age, the fracture risk was higher in type 2 diabetes patients than in those not presenting with type 2 diabetes [41].

\subsubsection{Age}

Age contributes, independently of BMD, to fracture risk; therefore, in the presence of the same BMD score, the risk of fracture will be higher for the elderly than for the young $[39,42]$. Another major problem regarding the elderly is their reduced muscular functionality. This is an age-related condition, but it is often exaggerated by deficient nutrition and reduced mobility. Weakness is one of the five items that define frailty syndrome as proposed by Fried and colleagues [43]. Moreover, the 'frail phenotype' is associated with a very high risk of falls leading to fracture [44].

\subsubsection{Previous Fractures}

The presence of a previous fracture, regardless of its site, is an important risk factor for further fractures and is independent of BMD. The most common prognostic fractures are those of the vertebrae, hip, humerus and wrist. Moreover, risk of further fracture increases with the number of previous fractures: patients with three or more previous fractures have a ten times greater risk of fracture than patients who have never suffered from fractures [1]. 
Table 3.2 Pathologies relevant to fracture risk

\begin{tabular}{|c|c|}
\hline Endocrine disorders & $\begin{array}{l}\text { - Hypogonadism } \\
\text { - Hypercortisolism } \\
\text { - Hyperparathyroidism } \\
\text { - Hyperthyroidism } \\
\text { - Hyperprolactinaemia } \\
\text { - Diabetes mellitus type I and II } \\
\text { - Acromegaly } \\
\text { - GH deficiency }\end{array}$ \\
\hline Haematological disorders & $\begin{array}{l}\text { - Myelo-lymphoproliferative diseases } \\
\text { - Multiple myeloma and monoclonal gammopathies } \\
\text { - Systemic mastocytosis } \\
\text { - Thalassemia } \\
\text { - Sickle-cell anaemia } \\
\text { - Haemophilia }\end{array}$ \\
\hline Gastrointestinal disorders & $\begin{array}{l}\text { - Chronic liver disease } \\
\text { - Primary biliary cirrhosis } \\
\text { - Celiac disease } \\
\text { - Chronic inflammatory bowel diseases } \\
\text { - Gastro-intestinal resection } \\
\text { - Gastric bypass } \\
\text { - Lactose intolerance } \\
\text { - Intestinal malabsorption } \\
\text { - Pancreatic insufficiency }\end{array}$ \\
\hline Rheumatological disorders & $\begin{array}{l}\text { - Rheumatoid arthritis } \\
\text { - LES } \\
\text { - Ankylosing spondylitis } \\
\text { - Psoriatic arthritis } \\
\text { - Scleroderma } \\
\text { - Other forms of connectivitis }\end{array}$ \\
\hline Renal disorders & $\begin{array}{l}\text { - Renal idiopathic hypercalciuria } \\
\text { - Renal tubular acidosis } \\
\text { - Chronic renal failure }\end{array}$ \\
\hline Neurological disorders & $\begin{array}{l}\text { - Parkinson's disease } \\
\text { - Multiple sclerosis } \\
\text { - Paraplegia } \\
\text { - Aftermath of stroke } \\
\text { - Muscular dystrophies }\end{array}$ \\
\hline Genetic disorders & $\begin{array}{l}\text { - Osteogenesis Imperfecta } \\
\text { - Ehlers-Danlos Syndrome } \\
\text { - Gaucher Syndrome } \\
\text { - Glycogenosis } \\
\text { - Hypophosphatasia } \\
\text { - Hemochromatosis } \\
\text { - Homocystinuria } \\
\text { - Cystic fibrosis } \\
\text { - Marfan Syndrome } \\
\text { - Menkes Syndrome } \\
\text { - Porphyria } \\
\text { - Riley-Day Syndrome }\end{array}$ \\
\hline Other pathologies & $\begin{array}{l}\text { - Chronic obstructive pulmonary disease } \\
\text { - Anorexia nervosa } \\
\text { - AIDS/HIV } \\
\text { - Amyloidosis } \\
\text { - Sarcoidosis } \\
\text { - Depression }\end{array}$ \\
\hline
\end{tabular}




\subsubsection{Family History of Fracture}

Family history influences fracture risk independently of BMD. In particular, parental hip fracture is significantly related to a higher risk of hip fractures in offspring and, to a lesser extent, of all other kinds of osteoporotic fractures [1].

\subsubsection{Comorbidities}

A broad range of pathologies is related to increased rates of fracture risk (Table 3.2).

In some cases, the increased fracture risk is caused by a reduction in BMD, but other mechanisms are often involved: chronic inflammation, alteration of bone quality, general impairment of health conditions, reduction of mobility, sarcopenia, with a higher risk of falls and other complications. Vitamin-D deficiency, which often coexists with this pathology, is another negative factor [1].

\subsubsection{Drugs}

Several drugs increase the risks of fracture. The most important class of drugs is glucocorticoids that have a negative effect on bone, causing rapid bone-quality loss and BMD depletion. Among the more recent classes of drugs, hormone-blockade treatments (aromatase inhibitors for women operated for breast cancer and GnRH agonists for men with prostate cancer) also lead to a reduction of BMD but at a slower rate. Other drugs involved are SSRI, PPI, H2 inhibitors, anticonvulsants, loop diuretics, anticoagulants, excess of thyroid hormones and antiretroviral treatment.

\subsubsection{Assessment of Fracture Risk}

Although BMD acts as the cornerstone when diagnosing osteoporosis, as mentioned earlier, the use of BMD alone does not suffice to identify an intervention threshold. This is why a vast number of scores are drawn up to better identify fracture risks; the most widely used assessment tool is FRAX ${ }^{\circledR}$. This is a web-based algorithm (www.shef.ac.uk/FRAX) which calculates the 10-year probability of a major fracture (hip, clinical spine, humerus or wrist) and a 10-year hip-fracture probability [45].

Despite the fact that international literature has demonstrated the validity of these instruments when evaluating the risk of fracture, the intervention thresholds for osteoporosis currently depend on regional treatment and reimbursement policies, which are increasingly based on cost-effectiveness evaluations [46-48].

For a more extensive discussion see Chap. 14. 


\subsection{Diagnosis}

There is no universally accepted population-screening policy in Europe for the recognition of patients with osteoporosis or those at high risk of fracture. In the absence of such a policy, patients are identified opportunistically using a case-finding strategy based on previous fragility fractures or the presence of significant risk factors [2].

\subsubsection{Instrumental Diagnosis}

Bone Mineral Density (BMD) may be evaluated by means of several techniques generally described as bone densitometry. Densitometry permits accurate measurement of bone mass, which is the best predictor of risks of osteoporotic fracture. The result is expressed as a T-score, which is the difference between the subject's BMD value and the mean BMD value for healthy young adults (peak bone mass) of the same sex, expressed in standard deviations (SD). BMD can also be expressed by comparing the average value for subjects of the same age and sex (Z-score). The threshold required to diagnose the presence of osteoporosis, according to the WHO, is a T-score of $<-2.5 \mathrm{SD}$.

\subsubsection{Dual X-Ray Absorptiometry (DXA)}

This is, at present, the technique preferred for bone-mass evaluation used to enable the diagnosis of osteoporosis, prediction of fracture risk and follow-up monitoring. The technique uses X-rays of two different energies, which allow the subtraction of soft tissue absorption and provide an estimate of the bone's calcium content. When projected onto a surface, this gives a parameter called bone mineral density (BMD $\left.\mathrm{g} / \mathrm{cm}^{2}\right)$, from which bone mineral content $\left(\mathrm{BMC}, \mathrm{g} / \mathrm{cm}^{3}\right)$ may be inferred. In general, measurement at a particular site provides a more accurate estimate of fracture risk for that site. Since the most clinically relevant osteoporotic fractures occur in the spine and hip, the most frequently measured sites are the lumbar spine and proximal femur. However, there are a number of technical limitations to the application of DXA to diagnosis. For example, the presence of osteomalacia will underestimate the total bone matrix because of decreased bone mineralisation while, on the other hand, osteoarthrosis or osteoarthritis of the spine or hip will contribute to density but not to skeletal strength [2]. In the latter case, the specific site involved must be excluded from the analysis; at least two lumbar vertebrae must be evaluated so that the densitometry result may be considered reasonably accurate. For this reason, femoral densitometric evaluation is probably preferable after the age of 65 . Recently some software has been developed to enable DXA to measure, not only BMD but also some of the geometrical parameters related to bone strength, such as HSA (hip structure analysis) and TBS (trabecular bone score).TBS has emerged as a novel grey-level texture measurement that uses experimental variograms of $2 \mathrm{D}$ projection images, quantifying variation in grey-level texture from one pixel to the adjacent pixels [49]. TBS is not a direct measurement of bone microarchitecture but is related 
to $3 \mathrm{D}$ bone characteristics such as the trabecular number, the trabecular separation and the connectivity density $[50,51]$. An elevated TBS appears to represent a strong, fracture-resistant microarchitecture, while a low TBS reflects a weak, fractureprone microarchitecture. As such, there is evidence that TBS can differentiate between two three-dimensional (3D) microarchitectures that exhibit the same bone density and different trabecular characteristics. Lumbar TBS, like a BMD, is an agedependent variable. Little change in TBS is observed between the ages of 30 and 45 years. Thereafter, a progressive decrease is observed with advancing age, which is more marked in women than in men. Although this device has been approved by the FDA, its everyday use in clinical practice is still limited [52].

\subsubsection{Quantitative Computerised Tomography (QCT)}

This technique, because it is able to separate the trabecular BMD from the cortical $\mathrm{BMD}$, permits total and local volumetric BMD $\left(\mathrm{g} / \mathrm{cm}^{3}\right)$ measurements at both vertebral and femoral levels. However, this method exposes patients to high radiation dose levels (about $100 \mathrm{~Sv}$ ). As a technique, DXA is usually preferred to QCT because of its accuracy, shorter scan times, more stable calibration, lower radiation dose and lower costs [2].

\subsubsection{Quantitative Ultra-Sound (QUS)}

This technique provides two parameters (speed and attenuation) which are indirect indicators of bone mass and structural integrity; it is used mainly to carry out measurements in two sites, the phalanges and the calcaneus. It has been demonstrated that ultrasound parameters are capable of predicting the risk of osteoporotic fractures (femoral and vertebral) no less accurately than lumbar or femoral DXA, both in postmenopausal women and in men, but this technique does not provide direct bone-density measurements. Discordant results between ultrasonographic and DXA evaluations are neither surprising nor infrequent and they do not necessarily indicate an error, but rather, that the QUS parameters are independent predictors of fracture risk influenced by other characteristics of the bone tissue. It does mean, however, that QUS cannot be used for the diagnoses of osteoporosis based on WHO criteria. QUS can be useful when it is not possible to estimate a lumbar or femoral BMD with DXA and may be recommended for epidemiological investigations and first-level screening, considering its relatively low cost, easy transportability and absence of radiation [2].

\subsubsection{X-Ray of the Dorsal and Lumbar Spine}

The presence of a non-traumatic vertebral fracture indicates a condition of skeletal fragility, regardless of BMD, and is a strong indicator of the need to start treatment to reduce risks of further fractures. Since most vertebral fractures are mild and asymptomatic, the use of diagnostic imaging is the only way to diagnose them. Vertebral fractures are defined, applying Genant's semi-quantitative method (SQ), more than a $20 \%$ reduction in one vertebral body height [2]. 


\subsubsection{Laboratory Tests}

Laboratory tests are an indispensable step in the diagnosis of osteoporosis because they can distinguish between this condition and other metabolic diseases of the skeleton, which may present a clinical picture similar to that of osteoporosis. Moreover, they can identify possible causal factors, permitting the diagnosis of secondary osteoporosis and suggesting an aetiological treatment where one exists. First-level tests are blood count, protein electrophoresis, serum-calcium and phosphorus levels, total alkaline phosphatase, creatinine, the erythrocyte sedimentation rate and $24 \mathrm{~h}$ urinary calcium. Normal results for these tests exclude up to $90 \%$ of secondary forms of osteoporosis. Sometimes it is necessary to perform second-level tests too, such as ionised calcium, TSH, PTH, serum 25-OH-vitamin D, cortisol after a suppression test with $1 \mathrm{mg}$ of dexamethasone, total testosterone in males, serum and/or urinary immunofixation for anti-transglutaminase antibodies and specific tests for associated diseases.

The specific markers of bone turnover, detectable in serum and/or urine, are divided into bone-formation (bone isoenzyme of alkaline phosphatase, osteocalcin, type I procollagen propeptide) and bone-resorption markers (pyridinoline, deoxypyridinoline, $\mathrm{N}$ or $\mathrm{C}$ telopeptides of collagen type I). In adult subjects, the increase in bone turnover markers indicates an accelerated bone loss or the existence of other primary or secondary skeletal disorders (osteomalacia, Paget's disease, skeletal localisations of cancer). Markers are overall indices of skeletal remodelling and they may be useful when monitoring the efficacy of and adherence to therapy. However, these markers are characterised by broad biological variability so, at present, they cannot be used for routine clinical evaluations [2].

\subsection{Management of Osteoporosis}

\subsubsection{Lifestyle Modification}

Giving up smoking and abuse of alcohol and choosing an active lifestyle is fundamental as a starting point for the management of a patient with osteoporosis.

Immobility is one of the most important causes of bone loss and should be avoided wherever possible. Weight-bearing exercises are optimal for skeletal health and are, therefore, an important component of the management of patients with osteoporosis [53].

\subsubsection{Prevention of Falls}

Risk factors for falls include a history of fracture/falls, dizziness and orthostatic hypotension, visual impairment, gait deficits, urinary incontinence, chronic musculoskeletal pain, depression, functional and cognitive impairment, low body mass index, female sex, erectile dysfunction (in male adults), and people aged over 80 [54]. Some of these factors are modifiable and it is important to act on them [55]. A programme of exercises may prevent falls by improving confidence and 
coordination and by preserving muscle strength but there is no consensus concerning the most suitable programme for the 'oldest old' $[55,56]$.

For a more extensive discussion of this issue see Chap. 16.

\subsection{The Importance of Vitamin D, Calcium and Protein Intake}

\subsubsection{Vitamin D}

Vitamin D is involved in the intestinal absorption of calcium and phosphorus and is necessary for mineralisation of the bone and the maintenance of the muscle, while also having numerous beneficial effects on other organs. Most Vitamin D is synthesised through the skin during exposure to the sun but this capacity is reduced in older people, moreover, they tend to expose their skin less than younger adults. Therefore, the majority of older people suffer from hypovitaminosis D [57]. The threshold values for vitamin D are presented below in Table 3.3. Several trials have demonstrated lower fracture risk in patients with a plasma concentration of 25-hydroxy-vitamin D (25$\mathrm{OH}-\mathrm{D})$ of at least $60 \mathrm{nmol} / \mathrm{L}$ [58]. It has been demonstrated that improvement in 25-OH-D levels leads to a lower incidence of falls in older people; other trials have demonstrated that vitamin D supplementation is associated with a reduction in allcause mortality [59]. The Recommended Nutrient Intakes (RNI) are 800 IU of vitamin D per day in men and women over 50 [2]. Intakes of at least $800 \mathrm{IU}$ of vitamin D can be recommended in the general management of patients with osteoporosis, especially in patients receiving bone-protective therapy [60]. Considering that hypovitaminosis D is an epidemic among the elderly, there is probably no strong necessity to measure circulating levels of 25-OH-D in patients with high fracture risk [57]. Vitamin D supplementation should start as soon as possible and should precede the administration of any drug used to treat osteoporosis [60]. Since the inactive form of vitamin D (cholecalciferol) is stored in fat tissue, it is sensible to saturate the stores with repeated small, loading doses and then to continue with maintenance doses.

\subsubsection{Calcium}

Calcium is an element necessary for the mineralisation of the bone. It is mainly contained in dairy products, which may have calcium and vitamin $\mathrm{D}$ added. The Recommended Nutrient Intakes (RNI) are a minimum of $1000 \mathrm{mg}$ of calcium per

Table 3.3 Threshold values of vitamin D [1]

\begin{tabular}{|l|l|l|}
\hline Serum vitamin D level $(\mathrm{nmol} / \mathrm{L})$ & Serum vitamin D level $(\mathrm{ng} / \mathrm{mL})$ & Definition \\
\hline$<25$ & $<10$ & Severe deficiency \\
\hline $25-50$ & $10-20$ & Deficiency \\
\hline $50-75$ & $20-30$ & Insufficiency \\
$75-125$ & $30-50$ & Target \\
\hline
\end{tabular}


day for men and women aged more than 50 years [2]. It is fundamental to ensure correct calcium intake by means of a balanced diet, but when this is not possible, calcium supplements of $0.5-1.2 \mathrm{~g}$ a day are recommended, especially in patients receiving bone-protective therapy $[4,61]$. Calcium and vitamin D supplements decrease secondary hyperparathyroidism thus reducing bone resorption. Although, in one meta-analysis, calcium supplementation seemed to increase the risk of myocardial infarction, although other studies contradict these results [62, 63].

For a more extensive discussion of this issue see Chap. 18.

\subsubsection{Protein}

Nutritional insufficiency - in particular protein-energy malnutrition-is frequent in the elderly. Adequate nutrition is very important for bone health [64]. The Insulinlike growth factor-I (IGF-I) mediates the effects of the growth hormone $(\mathrm{GH})$ and has promoting effects on several body tissues, especially on skeletal muscle, cartilage and bone. Moreover, it plays a role in the regulation of phosphate reabsorption in the kidney and the active uptake of $\mathrm{Ca} 2+$ and phosphate from the intestine via renal synthesis of calcitriol. In view of impaired protein assimilation in older people, for them, the RDA should be increased from $0.80 \mathrm{~g} / \mathrm{kg}$ body weight per day to 1.0 or $1.2 \mathrm{~g} / \mathrm{kg}$ per day [56].

For a more extensive discussion on nutritional aspects see Chap. 18.

For the pharmacological treatment at issue see Chap. 15.

\subsection{Therapeutic Adherence in Osteoporosis and the Role of Health Professionals}

Compelling research confirms that the vast majority of patients with osteoporosis, worldwide, are not treated or even diagnosed, because the disease often fails to manifest itself before a fracture occurs [65]. Unfortunately, even after fractures take place only a minority of patients receive prescriptions for adequate preventive treatment, either upon discharge from the hospital or over the following years. Research also demonstrates that although patients may have a good knowledge of what osteoporosis is, they generally have a low level of understanding of the role of medication in reducing fracture risk, various concerns about its side effects, poor understanding of the causes and risk factors of osteoporosis, and uncertainty about how it can be controlled [66].

An important epidemiological study by Rabenda and colleagues demonstrated that the medication possession ratio (MPR) at 12 months was higher among patients taking weekly, as compared to daily, doses of alendronate [67]. Adherence to therapeutic regimens is challenging, particularly for the elderly, who generally have a long list of drugs to take. They are often rather forgetful; it seems, however, that most instances of non-adherence are intentional, due to elderly patients carrying out an (erroneous) risk/benefit analysis on their behalf [68].

This situation obviously needs to be changed if we want to curtail the continuous expansion of the burden of osteoporotic fractures. New strategies and services, 
involving an enlarged group of health professionals and reliable mechanisms to articulate, foster and monitor their actions are needed. Nurses are often appointed as the key to the success of these services, due to their role in coordinating and communicating with other health professionals.[66].

Health professionals should provide education based on patient-centred care and create a mechanism that allows involvement of patients and families in their care, with particular focus on caring, patient communication, sharing of control over decisions, and the integration into the decision-making process of guidance by nurses, physicians, and other providers. It is important to explain to patients who have experienced a fracture that this was due to 'fragility' caused by osteoporosis and show them how drug treatment can help. It is fundamental to understand their reasons and excuses for not adhering to their medication programme.

Many studies show that people who actively seek to learn about and manage their health are more likely to take preventive healthy behaviour measures, self-manage their health conditions, adhere to the treatments prescribed, have better care experiences, and achieve better health outcomes.

Health care professionals should define a plan with the patient and family and provide education on dietary and lifestyle.

In general, periodic follow-up visits are beneficial: during which the patients should be asked to describe how they take their medicines while avoiding any notion of judgment [56].

\section{References}

1. Adami S, Bertoldo F, Brandi ML, Cepollaro C, Filipponi P, Fiore E, Frediani B, Giannini S et al (2009) Guidelines for the diagnosis, prevention and treatment of osteoporosis. Reumatismo 61:260-284

2. Kanis J, McCloskey E, Johansson H, Cooper C, Rizzoli R, Reginster J et al (2013) European guidance for the diagnosis and management of osteoporosis in postmenopausal women. Osteoporos Int 24:23-57

3. Kanis J, Borgstrom F, De Leat C, Johansson H, Johnell O, Jonsson B, Odea A, Zethraeus N, Pfleger B, Khaltaev N et al (2005) Assessment of fracture risk. Osteoporos Int 16:581-589

4. Strom O, Borgstrom F, Kanis J, Compston J, Cooper C, McCloskey E, Jonsson B (2011) Osteoporosis: burden, healthcare provision and opportunities in the EU. A report prepared in collaboration with the International Osteoporosis Foundation (IOF) and the European Federation of Pharmaceutical Industry Associations (EFPIA). Arch Osteoporos 6:59-155

5. Kanis J, Compston J, Cooper C et al (2012) The burden of fractures in the European Union in 2010. Osteoporos Int 23:S57

6. Cooper C, Atkinson E, Jacobsen S, O'Fallon W, Melton L (1993) Population-based study of survival after osteoporotic fractures. Am J Epidemiol 137:1001-1005

7. Kanis J, Oden A, Johnell O, De Laet C, Jonsson B, Oglesby A (2003) The components of excess mortality after hip fracture. Bone 32:468-473

8. Clarke B (2008) Normal bone anatomy and physiology. Clin J Am Soc Nephrol 3(Suppl 3):S131-S139

9. Boyle WJ, Simonet WS, Lacey DL (2003) Osteoclast differentiation and activation. Nature 423:337-342

10. Brodsky B, Persikov AV (2005) Molecular structure of the collagen triple helix. Adv Protein Chem 70:301-339

11. Bouxsein ML (2003) Bone quality: where do we go from here? Osteoporos Int 14(Suppl 5):118-127 
12. Felsenberg D, Boonen S (2005) The bone quality framework: determinants of bone strength and their interrelationships, and implications for osteoporosis management. Clin Ther 27:1-11

13. Jarvinen TL, Sievanen H, Jokihaara J, Einhorn TA (2005) Revival of bone strength: the bottom line. J Bone Miner Res 20:717-720

14. Hernandez CJ, Keaveny TM (2006) A biomechanical perspective on bone quality. Bone 39(6):1173-1181

15. Kobayashi S, Takahashi HE, Ito A, Saito N, Nawata M, Horiuchi H, Ohta H, Ito A, Iorio R, Yamamoto N, Takaoka K (2003) Trabecular minimodeling in human iliac bone. Bone 32:163-169

16. Burr DB (2002) Targeted and nontargeted remodeling. Bone 30:2-4

17. Parfitt AM (2002) Targeted and nontargeted bone remodeling: relationship to basic multicellular unit origination and progression. Bone 30:5-7

18. Blair HC, Athanasou NA (2004) Recent advances in osteoclast biology and pathological bone resorption. Histol Histopathol 19:189-199

19. Reddy SV (2004) Regulatory mechanisms operative in osteoclasts. Crit Rev Eukaryot Gene Expr 14:255-270

20. Hock JM, Centrella M, Canalis E (2004) Insulin-like growth factor I (IGF-I) has independent effects on bone matrix formation and cell replication. Endocrinology 122:254-260

21. Martin TJ, Sims NA (2005) Osteoclast-derived activity in the coupling of bone formation to resorption. Trends Mol Med 11:76-81

22. Anderson HC (2003) Matrix vesicles and calcification. Curr Rheumatol Rep 5:222-226

23. Burger EH, Klein-Nuland J, Smit TH (2003) Strain-derived canalicular fluid flow regulates osteoclast activity in a remodeling osteon: a proposal. J Biomech 36:1452-1459

24. Delgado-Calle J, Sato AY, Bellido T (2017) Role and mechanism of action of Sclerostin in bone. Bone 96:29-37

25. Baron R, Kneissel M (2013) WNT signaling in bone homeostasis and disease: from human mutations to treatments. Nat Med 19(2):179-192

26. Gori F, Lerner U, Ohlsson C, Baron R (2015) A new WNT on the bone: WNT16, cortical bone thickness, porosity and fractures. Bonekey Rep 4:669

27. Poole KE, Van Bezooijen RL, Loveridge N, Hamersma H, Papapoulos SE, Lowik CW et al (2005) Sclerostin is a delayed secreted product of osteocytes that inhibits bone formation. FASEB J 19(13): 1842-1844

28. Li X, Zhang Y, Kang H, Liu W, Liu P, Zhang J et al (2005) Sclerostin binds to LRP5/6 and antagonizes canonical Wntsignaling. J Biol Chem 280(20):19883-19887

29. Leupin O, Piters E, Halleux C, Hu S, Kramer I, Morvan F et al (2011) Bone overgrowthassociated mutations in the LRP4 gene impair sclerostin facilitator function. J Biol Chem 286(22):19489-19500

30. Boyce BF, Xing L (2008) Functions of RANKL/RANK/OPG in bone modeling and remodeling. Arch Biochem Biophys 473(2):139-146

31. Glass DA, Bialek P, Ahn JD, Starbuck M, Patel MS, Clevers H et al (2005) Canonical Wnt signaling in differentiated osteoblasts controls osteoclast differentiation. Dev Cell 8(5):751-764

32. Holmen SL, Zylstra CR, Mukherjee A, Sigler RE, Faugere MC, Bouxsein ML et al (2005) Essential role of beta-catenin in postnatal bone acquisition. J Biol Chem 280(22):21162-21168

33. Kramer I, Halleux C, Keller H, Pegurri M, Gooi JH, Weber PB et al (2010) Osteocyte Wnt/betacatenin signaling is required for normal bone homeostasis. Mol Cell Biol 30(12):3071-3085

34. Stolina M, Dwyer D, Niu QT, Villasenor KS, Kurimoto P, Grisanti M et al (2014) Temporal changes in systemic and local expression of bone turnover markers during six months of sclerostin antibody administration to ovariectomized rats. Bone 67:305-313

35. Bono CM, Einhorn TA (2003) Overview of osteoporosis: pathophysiology and determinants of bone strength. Eur Spine J 12(Suppl. 2):S90-S96

36. Grzibovskis M, Pilmane M, Urtane I (2010) Today's understanding about bone aging. Stomatologija 12:99-104

37. Raisz LG (2007) Maintaining the life-long vitality and integrity of skeletal tissue. Bone 40(Suppl 1):S1-S4

38. Eastell R, Lambert H (2002) Strategies for skeletal health in the elderly. Proc Nutr Soc 61:173-180 
39. Kanis J, Johnell O, Oden A, Dawson A, De Laet C, Jonsson B (2001) Ten year probabilities of osteoporotic fractures according to BMD and diagnostic thresholds. Osteoporos Int 12(12):989-995

40. Miller P, Barlas S, Brenneman S, Abbott T, Chen Y, Barrett-Connor E, Siris E (2004) An approach to identifying osteopenic women at increased short-term risk of fracture. Arch Intern Med 164:1113-1120

41. Ferrari SL, Abrahamsen B, Napoli N, Akesson K, Chandran M, Eastell R, El-Hajj Fuleihan G, Josse R, Kendler DL, Kraenzlin M, Suzuki A, Pierroz DD, Schwartz AV, Leslie WD, on behalf of the Bone and Diabetes Working Group of IOF (2018) Diagnosis and management of bone fragility in diabetes: an emerging challenge. Osteoporos Int 29(12):2585-2596

42. Hui S, Slemenda C, Johnston C (1998) Age and bone mass as predictors of fracture in a prospective study. J Clin Invest 81:1804-1809

43. Fried L, Tangen C, Walston J, Newman A, Hirsch C, Gottdiener J, Seeman T, Tracy R, Kop W, Burke G, McBurnie M (2001) Frailty in older adults: evidence for a phenotype. J Gerontol ABiol Sci Med Sci 56:M146-M156

44. Tom S, Adachi J, Anderson F Jr, Boonen S, Chapurlat R, Compston J, Cooper C, Gehlbach S, Greenspan S, Hooven F, Nieves J, Pfeilschifter J, Roux C, Silverman S, Wyman A, La Croix A (2013) Frailty and fracture, disability, and falls: a multiple country study from the global longitudinal study of osteoporosis in women. J Am Geriatr Soc 61:327-334

45. Kanis J, Johnell O, Oden A, Johansson H, McCloskey E (2008) FRAX and the assessment of fracture probability in men and women from UK. Osteoporos Int 19:385-397

46. Kanis J, Hans D, Cooper C et al (2011) Interpretation and use of FRAX in clinical practice. Osteoporos Int 22:2395-2411

47. Leslie W, Lix L, Johansson H, Oden A, McCloskey E, Kanis J (2011) Spine-hip discordance and fracture risk assessment: a physician-friendly FRAX enhancement. Osteoporos Int 22:839-847

48. Hiligsmann M, Kanis J, Compston J, Cooper C, Flamion B, Bergmann P, Body J, Boonen S, Bruyere ODJ, Goemaere S, Kaufman J, Rozenberg S, Reginster J (2013) Health technology assessment in osteoporosis. Calcif Tissue Int 93:1-14

49. Harvey NC, Glüer CC, Binkley N, McCloskey MV, Brandi ML, Cooper C, Kendler D, Lamy O, Laslop A, Camargos BM, Reginster JY, Rizzoli R, Kanis JA (2015) Trabecular bone score (TBS) as a new complementary approach for osteoporosis evaluation in clinical practice: a consensus report of a European Society for Clinical and Economic Aspects of Osteoporosis and Osteoarthritis (ESCEO) Working Group. Bone 78:216-224

50. Hans D, Goertzen AL, Krieg M-A, Leslie WD (2011) Bone micro-architecture assessed by TBS predicts osteoporotic fractures independent of bone density: the Manitoba study. J Bone Miner Res 26:2762-2769

51. Winzenrieth R, Michelet F, Hans D (2013) Three-dimensional (3D) microarchitecture correlations with 2D projection image gray-level variations assessed by trabecular bone score using high-resolution computed tomographic acquisitions: effects of resolution and noise. J Clin Densitom 16:287-296

52. Simonelli C, Leib E, Mossman N, Winzenrieth R, Hans D, McClung M (2014) Creation of an age-adjusted, dual-energy x-ray absorptiometry-derived trabecular bone score curve for the lumbar spine in non-Hispanic US White women. J Clin Densitom 17:314-319

53. Howe T, Rochester L, Neil F, Skelton D, Ballinger C (2011) Exercise for improving balance in older people. Cochrane Database Syst Rev (11):CD004963. https://doi.org/10.1002/14651858

54. AGS/BGS/AAOS (2001) Guideline for the prevention of falls in older persons. American Geriatrics Society, British Geriatrics Society, and American Academy of Orthopaedic Surgeons Panel on Falls Prevention. J Am Geriatr Soc 49:664-672

55. Michael Y, Whitlock E, Lin J, Fu R, O’Connor E, Gold R (2010) Primary care-relevant interventions to prevent falling in older adults: a systematic evidence review for the U.S. Preventive Services Task Force. Ann Intern Med 153:815-825

56. Rizzoli R, Branco J, Brandi M, Boonen S, Bruyère O, Cacoub P, Cooper C (2014) Management of osteoporosis of the oldest old. Osteoporos Int 25:2507-2529

57. Boucher B (2012) The problems of vitamin D insufficiency in older people. Aging Dis 3:313-329 
58. Bischoff-Ferrari H, Willett W, Orav E, Lips P, Meunier P, Lyons R, Flicker L, Wark J, Jackson R, Cauley J, Meyer H, Pfeifer M, Sanders K, Stahelin H, Theiler R, Dawson-Hughes B (2012) A pooled analysis of vitamin D dose requirements for fracture prevention. N Engl J Med 367:40-49

59. Bischoff-Ferrari H, Dawson-Hughes B, Staehelin H, Orav J, Stuck A, Theiler R, Wong J, Egli A, Kiel D, Henschkowski J (2009) Fall prevention with supplemental and active forms of vitamin D: a meta-analysis of randomised controlled trials. BMJ 339:b3692. https://doi. org/10.1136/bmj.b3692

60. Rizzoli R, Boonen S, Brandi N, Bruyer O, Cooper C, Kanis J, Kaufman J, Ringe J, Weryha G, Reginster J (2013) Vitamin D supplementation in elderly or postmenopausal women: a 2013 update of 2008 reccomandations from the European Society for Clinical and Economic Aspects of Osteoporosis and Osteoarthritis (ESCEO). Curr Med Res Opin 29:305-313

61. Bischoff-Ferrari H, Kiel D, Dawson-Hughes B, Orav J, Li R, Spiegelman D, Dietrich T, Willett W (2009) Dietary calcium and serum 25-hydroxyvitamin D status in relation to BMD among U.S. adults. J Bone Miner Res 24:935-942

62. Bolland M, Avenell A, Baron J, Grey A, MacLennan G, Gamble G, Reid I (2010) Effect of calcium supplements on risk of myocardial infarction and cardiovascular events: metaanalysis. BMJ 341:c3691

63. Burckhardt P (2011) Potential negative cardiovascular effects of calcium supplements. Osteoporos Int 22:1645-1647

64. Genaro P, Martini L (2010) Effect of protein intake on bone and muscle mass in the elderly. Nutr Rev 68:616-623

65. Eisman JA, Bogoch ER, Dell R, Harrington JT, McKinney RE Jr, McLellan A, Mitchell PJ, Silverman S, Singleton R, Siris E (2012) Making the first fracture the last fracture: ASBMR task force report on secondary fracture prevention. J Bone Miner Res 27:2039-2046

66. Conley RB, Adib G, Adler RA, Akesson KE, Alexander IM, Amenta KC, Blank RD, Brox WT, Carmody EE, Chapman-Novakofski K, Clarke BL, Cody KM, Cooper C, Crandall CJ, Dirschl DR, Eagen TJ, Elderkin AL, Fujita M, Greenspan SL, Halbout P, Hochberg MC, Javaid M, Jeray KJ, Kearns AE, King T, Koinis TF, Koontz JS, Kuzma M, Lindsey C, Lorentzon M, Lyritis GP, Michaud LB, Miciano A, Morin SN, Mujahid N, Napoli N, Olenginski TP, Puzas JE, Rizou S, Rosen CJ, Saag K, Thompson E, Tosi LL, Tracer H, Khosla S, Kiel D (2020) Secondary fracture prevention: consensus clinical recommendations from a multistakeholder coalition. J Bsone Miner Res 35:36-52. https://doi.org/10.1002/jbmr.3877

67. Rabenda V, Mertens R, Fabri V, Vanoverloop J, Sumkay F, Vannecke C, Deswaef A, Verpooten G, Reginster JY (2008) Adherence to bisphosphonates therapy and hip fracture risk in osteoporotic women. Osteoporos Int 19:811-818

68. Tafaro L, Nati G, Leoni E, Baldini R, Cattaruzza MS, Mei M, Falaschi P (2013) Adherence to anti-osteoporotic therapies: role and determinants of "spot therapy". Osteoporos Int 24(8):2319-2323

Open Access This book is licensed under the terms of the Creative Commons AttributionNonCommercial-NoDerivatives 4.0 International License (http://creativecommons.org/licenses/ by-nc-nd/4.0/), which permits any noncommercial use, sharing, distribution and reproduction in any medium or format, as long as you give appropriate credit to the original author(s) and the source, provide a link to the Creative Commons license and indicate if you modified the licensed material. You do not have permission under this license to share adapted material derived from this book or parts of it.

The images or other third party material in this book are included in the book's Creative Commons license, unless indicated otherwise in a credit line to the material. If material is not included in the book's Creative Commons license and your intended use is not permitted by statutory regulation or exceeds the permitted use, you will need to obtain permission directly from the copyright holder. 